\title{
Prevalence of antenatal vulvovaginal candidiasis: our experience
}

\author{
Arul Anne Rose S. ${ }^{*}$, Sony Paul ${ }^{2}$, Iyanar Kannan²
}

\begin{abstract}
${ }^{1}$ Department of Obstetrics and Gynecology, Tagore Medical College and Hospital, The Tamilnadu Dr. MGR Medical University, Rathinamangalam, Chennai -127, India

${ }^{2}$ Department of Microbiology, Tagore Medical College and Hospital, The Tamilnadu Dr. MGR Medical University, Rathinamangalam, Chennai -127, India
\end{abstract}

Received: 27 December 2016

Accepted: 02 January 2017

\section{*Correspondence:}

Dr. Arul Anne Rose S.,

E-mail: annejoan04@gmail.com

Copyright: (c) the author(s), publisher and licensee Medip Academy. This is an open-access article distributed under the terms of the Creative Commons Attribution Non-Commercial License, which permits unrestricted non-commercial use, distribution, and reproduction in any medium, provided the original work is properly cited.

\begin{abstract}
Background: The objective of our study is to determine the prevalence of vulvovaginal candidiasis and influence of maternal age, parity or trimester on its occurrence among pregnant women, attending the antenatal clinic in our teaching hospital. It helps us to understand the magnitude of the problem in our region and to implement the necessary treatment modalities to reduce the preterm births attributed to vaginal candidiasis.

Methods: It was a hospital based prospective study over a period of six months. High vaginal swabs were collected from the pregnant patients after getting consent and sent for culture. Candida positive cases were noted and results were analysed.

Results: A total of 200 high vaginal swabs were collected and reported in our study. Among them 108 swabs were positive for Candida growth (54\%) and 92 swabs were negative for growth (46\%). Culture positive patients clinical details were analyzed and statistical significance was noted (based on age group, parity and trimester).

Conclusions: Our study concluded that candidiasis is more prevalent in pregnant women but there was no statistical significance in occurrence of vaginal candidiasis among various age groups, parity or trimester. Hence it is better to screen all the patients in I/ early II trimester in order to find out and treat positive cases early to prevent preterm births attributed to vaginal candidiasis.
\end{abstract}

Keywords: Preterm birth, Pregnancy, Vulvo vaginal candidiasis

\section{INTRODUCTION}

Prevention of preterm birth remains one of the greatest challenges in present day Obstetrics. Several factors indicate an association between vaginal candidiasis and preterm births. ${ }^{1,2}$ Candida can be isolated from the amniotic fluid of the pregnant women with preterm deliveries. ${ }^{3,4}$

Candida species colonises the vagina in $20 \%$ of all women, which rises to $30 \%$ in pregnancy. ${ }^{5}$ Vaginal candidiasis is due to Candida albicans in $85-95 \%$ of cases. $^{6,7}$ In less than $10 \%$ of cases, non-albicans, like
Candida glabrata, Candida tropicalis, etc. cause vulvovaginitis, often with fewer clinical features. 5,6

Recently, studies showed that Candidiasis in pregnancy may be associated with an increased risk of pregnancy complications like premature rupture of membranes and poor pregnancy outcomes. ${ }^{8,9}$ There is an emerging evidence that eradication of candida during pregnancy may decrease the risk of preterm births and late miscarriages..$^{1,10}$

If preterm births are reduced significantly, it will be reflected in reduction of the need of the neonatal 
facilities, hospitalization and prolonged care for preterm babies. In addition it also reduces the financial burden for the patients and health sectors.

The objective of our study is to determine the prevalence of vulvovaginal candidiasis among pregnant women, attending the antenatal clinic in our teaching hospital. It helps us to understand the magnitude of the problem in our region and to implement the necessary treatment modalities to reduce the preterm births.

\section{METHODS}

The study was a hospital based prospective study conducted in our teaching medical college and hospital over a period of 6 months (March 2015-August 2015).The study was conducted after getting permission from our Institutional Ethical Committee. The study population was selected from the patients who were attending the antenatal outpatient department after getting the detailed informed consent.

A detailed clinical history was taken from the patients; age, parity, presence or absence of symptoms (vaginal discharge, itching or burning) and risk factors (diabetes, use of antibiotics in the past, previous history of candidiasis and history of immunosuppression) associated with vaginal candidiasis were recorded. Under sterile precautions high vaginal swabs were taken, placed immediately in the case, labelled and sent to Department of Microbiology for growth.
In Candida positive cultures, Candida albicans or nonalbicans were differentiated and recorded. Growth results were recorded with patient details.

The results were statistically analysed with SPSS software version 20.0.

\section{RESULTS}

A total of 200 high vaginal swabs were collected and reported in our study. Among them 108 swabs were positive for Candida growth $(54 \%)$ and 92 swabs were negative for growth (46\%) (Table 1).

Table 1: Prevalence of vaginal candidiasis in pregnant women.

\begin{tabular}{|lll|}
\hline Culture & $\begin{array}{l}\text { Number of } \\
\text { pregnant women }\end{array}$ & $\begin{array}{l}\text { Percentage } \\
(\%)\end{array}$ \\
\hline Positive & 108 & $54 \%$ \\
\hline Negative & 92 & $46 \%$ \\
\hline Total & 200 & $100 \%$ \\
\hline
\end{tabular}

Culture positive patients clinical details were analysed and results were given below (based on age group, parity, and trimester).

The highest number of positive cases were found to be in 30-34 years of age group (56.4\%) followed by 20 24 years $(54.5 \%)$ and $25-29$ years $(52.8 \%)$ (Table 2$)$.

Table 2: Distribution of vaginal candidiasis among different age groups.

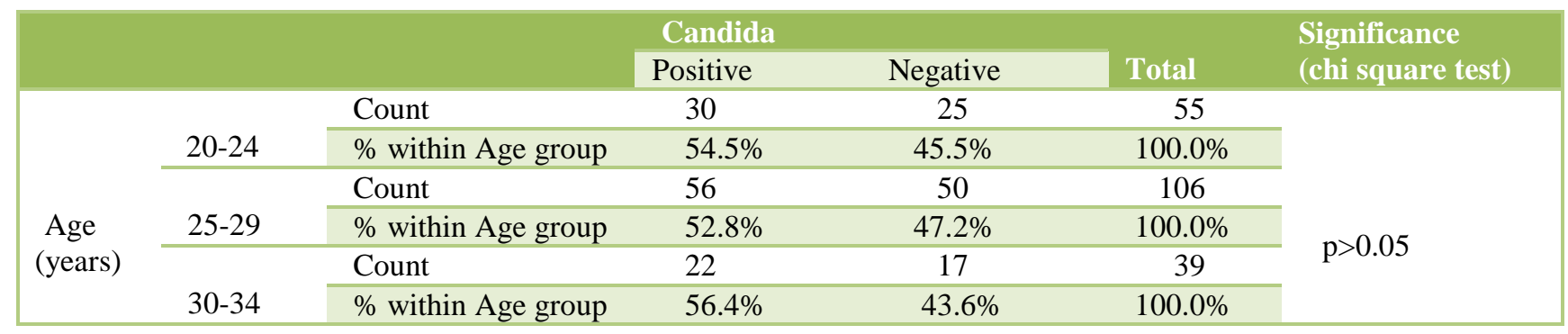

Table 3: Distribution of vaginal candidiasis in relation to parity.

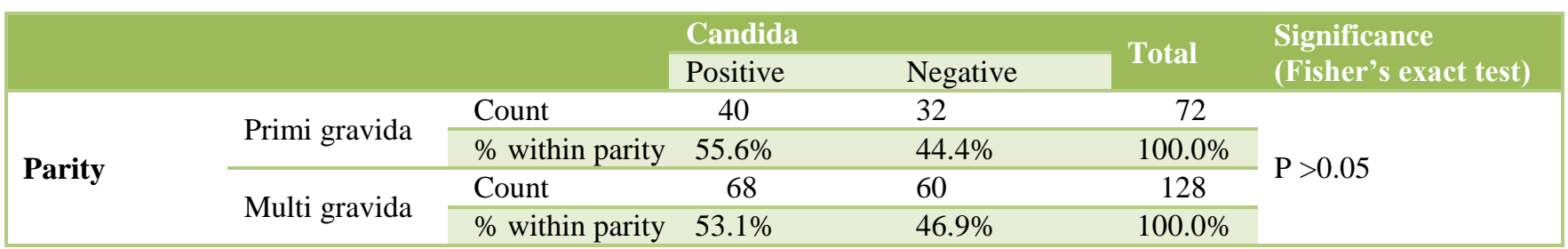

When we analysed the results in relation to parity, $55.6 \%$ of cases of primi gravida were positive and $53.1 \%$ of multi gravida were positive for candida (Table 3). In relation to trimester, the highest number of positive cases was in II trimester (58.5\%) followed by I trimester $(53.2 \%)$ and III trimester $(50.7 \%)$ (Table 4$)$. But the results are not statistically significant when compared to 
controls in relation to particular age group, parity or trimester.

$58 \%$ of candida positive women were symptomatic and the remaining $42 \%$ were asymptomatic. $34 \%$ of pregnant women with vaginal candidiasis had at least one of the risk factors. Isolation of species was done in positive patients. Candida albicans was the predominant species in $58 \%$ of patients followed by non albicans in $42 \%$ of patients.

Table 4: Distribution of vaginal candidiasis among different trimesters.

\begin{tabular}{|c|c|c|c|c|c|c|}
\hline & & & \multicolumn{2}{|l|}{ Candida } & \multirow[b]{2}{*}{ Total } & \multirow{2}{*}{$\begin{array}{l}\text { Significance } \\
\text { (chi-square } \\
\text { test) }\end{array}$} \\
\hline & & & Positive & Negative & & \\
\hline \multirow{6}{*}{ Trimester } & \multirow{2}{*}{ First } & Count & 33 & 29 & 62 & \multirow{6}{*}{$\mathrm{P}>0.05$} \\
\hline & & $\%$ within trimester & $53.2 \%$ & $46.8 \%$ & $100.0 \%$ & \\
\hline & \multirow{2}{*}{ Second } & Count & 38 & 27 & 65 & \\
\hline & & $\%$ within trimester & $58.5 \%$ & $41.5 \%$ & $100.0 \%$ & \\
\hline & \multirow{2}{*}{ Third } & Count & 37 & 36 & 73 & \\
\hline & & $\%$ within trimester & $50.7 \%$ & $49.3 \%$ & $100.0 \%$ & \\
\hline
\end{tabular}

\section{DISCUSSION}

Pregnant women have two fold increases in the prevalence of vaginal candidiasis when compared to nonpregnant women. ${ }^{6}$

Vulvo vaginal candidiasis is an important cause of morbidity in pregnancy which can result in miscarriages, candida chorioamnionitis, subsequent preterm delivery and emotional stress. ${ }^{11-13}$

Early detection and diagnosis may improve the clinical condition of the pregnant women and reduces the number of preterm term births significantly. If preterm births are reduced significantly, it will be reflected in reduction of the need of the neonatal facilities, hospitalisation and prolonged care for preterm babies. In addition, it also reduces the financial burden for the patients and health sectors.

In our study, the highest number of positive cases were found to be in 30-34years of age group $(56.4 \%)$ followed by $20-24$ years $(54.5 \%)$ and $25-29$ years $(52.8 \%)$.

In relation to parity, $55.6 \%$ of cases of primi gravida were positive and $53.1 \%$ of multi gravida were positive for candida. In relation to trimester, the highest number of positive cases was in II trimester $(58.5 \%)$ followed by I trimester $(53.2 \%)$ and III trimester $(50.7 \%)$. But the results are not statistically significant when compared to controls in relation to particular age group, parity or trimester.

Even though many studies showed higher prevalence of vaginal candidiasis in the age group of 21-30 years, multigravida and II trimester, our study did not reveal any statistical significance in these groups and supported by few other studies also. ${ }^{14-21}$
$58 \%$ of candida positive women were symptomatic and the remaining $42 \%$ were asymptomatic. $34 \%$ of pregnant women with vaginal candidiasis had at least one of the risk factors. Isolation of species was done in positive patients. Candida albicans was the predominant species in $58 \%$ of patients followed by non albicans in $42 \%$ of patients.

As preterm labour is a result of chronic inflammatory process, it is better to screen all patients in early /mid II trimester to pick up the cases early to initiate the treatment. The safety of any proposed intervention in pregnancy is of great importance. Clotrimazole is classified as category A drug, which has been used by large number of pregnant women without any proven increase in the frequency of malformation or harmful effects on the fetus. ${ }^{22,23}$

Local application of clotrimazole vaginal passerines or cream is generally well tolerated, can be used for 6 days which is supported by the Cochrane Systematic Review of treatment for candida eradication in pregnancy and was the regimen used in the kiss trial. ${ }^{1,24}$ As there is a high prevalence of vaginal candidiasis in pregnancy and its associated complications, it is better to screen all pregnant women and treat the positive patients.

\section{CONCLUSION}

Our study concluded that vaginal candidiasis is more prevalent in pregnant women but there was no statistical significance in occurrence of vaginal candidiasis among various age groups, parity or trimester. Hence, it is better to screen all the patients in I/early II trimester in order to find out and treat positive cases early to prevent preterm births attributed to vaginal candidiasis. 
Funding: No funding sources

Conflict of interest: None declared

Ethical approval: The study was approved by the Institutional Ethics Committee

\section{REFERENCES}

1. Kiss H, Petricevic L, Husslein P. Prospective randomised controlled trial of an infection screening programme to reduce the rate of preterm delivery. British Medical Journal. 2004;329(7462):371.

2. Cotch MF, Hillier SL, Gibbs RS, Eschenbach DA. Epidemiology and outcomes associated with moderate to heavy Candida colonization during pregnancy. Vaginal Infections and Prematurity Study Group. Am J Obstet Gynecol. 1998; 178 (2):374-80.

3. Chaim W, Mazor M, Wiznitzer A. The prevalence and clinical significance of intraamniotic infection with Candida species in women with preterm labor. Arch Gynecol Obstet. 1992;251(1):9-15.

4. Figueroa R, Garry D, Elimian A, Patel K, Sehgal PB, Tejani N. Evaluation of amniotic fluid cytokines in preterm labor and intact membranes. J Matern Fetal Neonatal Med. 2005;18(4):241-7.

5. Mendling W, Brasch J. German Society for Gynecology and Obstetrics; Working Group for Infections and Infect immunology in Gynecology and Obstetrics; German Society of Dermatology, the Board of German Dermatologists; German Speaking Mycological Society. 2010.

6. Guideline vulvovaginal candidiasis of the German Society for Gynecology and Obstetrics, the Working Group for Infections and Infect immunology in Gynecology and Obstetrics, the German Society of Dermatology, the Board of German Dermatologists and the German Speaking Mycological Society. Mycoses. 2012;55 (Suppl 3):1-13.

7. Sobel JD. Vulvovaginal candidosis. Lancet. 2007;369(9577):1961-71.

8. Fardiazar Z, Ronaci F, Torab R, Goldust M. Vulvovaginitis candidiasis recurrence during pregnancy. Pak J Biol Sci. 2012;15(8):399-402.

9. Ilkit M, Guzel AB. The epidemiology, pathogenesis, and diagnosis of vulvovaginal candidosis: a mycological perspective. Crit Rev Microbiol. 2011;37(3):250-61.

10. Mazor M, Chaim W, Shinwell ES, Glezerman M. Asymptomatic amniotic fluid invasion with Candida albicans in preterm premature rupture of membranes. Implications for obstetric and neonatal management. Acta Obstet Gynecol Scand. 1993;72(1):52-4.

11. Morrison EA, Cushman LF. Prevention of preterm delivery. N Engl J Med. 2007;357(19):1979.

12. Singh SI. Treatment of vulvovaginal candidiasis. Clin. Rev. CPJ/RPC. 2014;136(9):26-30.
13. Sobel JD. Vaginitis the New England journal of medicine. 1997;(337):1896-903.

14. Sobel JD. Epidemiology and pathogenesis of recurrent vulvovaginal candidiasis. Am J Obstet Gynecol. 1985;152(7 Pt 2):924-35.

15. Nelson M, Wanjiru W. Prevalence of Vaginal Candidiasis and Determination of the Occurrence of Candida Species in Pregnant Women Attending the Antenatal Clinic of Thika District Hospital, Kenya. Open Journal of Medical Microbiology. 2013;3(4):264-72.

16. Kanagal DV, Vineeth VK, Kundapur R, Shetty H, Rajesh A. Prevalence of Vaginal Candidiasis in Pregnancy among Coastal South Indian Women. J Womens Health, Issues Care. 2014;3:6.

17. Sparks RA, Williams GL, Boyce JM. Antenatal screening for candidiasis, trichomoniasis, and gonorrhoea. Br J Vener Dis. 1975;51(2):110-15.

18. Aslam M, Hafeez R, Ijaz S, Tahir M. Vulvovaginal Candidiasis in Pregnancy. Biomedica. 2008;24:54-6.

19. Parveen N, Munir AA. Frequency of vaginal candidiasis in pregnant women attending routine antenatal. clinic. J Coll Physicians Surg Pak. 2008;18(3).

20. Oyewole O, Okoliegbe IN. Prevalence of vaginal candidiasis among pregnant women attending Federal University of Technology, Minna, Nigeria, Bosso Clinic. Research Journal of Pharmaceutical, Biological and Chemical Sciences. 2013;4(1):11320.

21. Yadav K, Prakash S. Prevalence of vulvovaginal candidiasis in pregnancy. Global Journal of Medicine and Medical Sciences. 2016;4(1):108-16.

22. Nurat AA, Babalola GO, Shittu MO. Detection and Epidemiology of Vulvovaginal Candidiasis among Asymptomatic Pregnant Women Attending a Tertiary Hospital in Ogbomoso, Nigeria. International Journal of Biomedical Research. 2015;6(7).

23. Czeizel AE, Tóth M, Rockenbauer M. No teratogenic effect after clotrimazole therapy during pregnancy. Epidemiology. 1999;10(4):437-40.

24. Rosa FW, Baum C, Shaw M. Pregnancy outcomes after first-trimester vaginitis drug therapy. Obstet Gynecol. 1987;69(5):751-5.

25. Young GL, Jewell D. Topical treatment for vaginal candidiasis (thrush) in pregnancy. Cochrane Database Syst Rev. 2001;4:CD000225.

Cite this article as: Arul Anne Rose S, Paul S, Kannan I. Prevalence of antenatal vulvovaginal candidiasis: our experience. Int J Reprod Contracept Obstet Gynecol 2017;6:443-6. 